\title{
A Dance Between Chaos and Complexity: Choreographing the Spasm in Music Videos ${ }^{1}$
}

Melissa Blanco Borelli, Royal Holloway University of London

\begin{abstract}
This article analyzes the use of the spasm as a choreographic tool in the following music videos: The Talking Heads' "Once in a Lifetime" (1981), Radiohead's "Lotus Flower" (2011), and Atoms for Peace's "Ingenue" (2013). I read the choreography in these videos as representations of the spasm (as defined by Franco 'Bifo' Berardi) which can ultimately become a chaoide (as defined by Gilles Deleuze and Félix Guattari) when deployed in specific ways by specific bodies. My analysis of these videos suggests opportunities for thinking about how the corporeal labor of the spasm-especially its contingent sweat alongside (un)successful moments of corporeal fluidity-mark bodies as agents capable of negotiating how they might control their own embodied relationship to semiocapitalism and its privileging of speed and productivity.
\end{abstract}

Keywords: spasm, chaoide, chaosmosis, dance in music videos, semiocapitalism

This article engages with the concepts of the spasm (Franco 'Bifo' Berardi) and the chaoide (Gilles Deleuze and Félix Guattari) to analyze the dancing in three music videos curated in order to demonstrate the progression of the spasm as a corporeal gesture brought upon by neoliberal semiocapitalism: The Talking Heads' "Once in a Lifetime" (1981), Radiohead's "Lotus Flower" (2011) and Atoms for Peace's "Ingenue" (2013). My understanding of neoliberalism comes from David Harvey in A Brief History of Neoliberalism (2005) where he argues that neoliberalism is "in the first instance a theory of political economic practices that proposes that human well-being can best be advanced by liberating individual entrepreneurial freedoms and skills within an institutional framework characterized by strong private property rights, free markets, and free trade." ${ }^{2}$ Beginning in the late 1970s and gaining traction by late $80 \mathrm{~s}$ and $90 \mathrm{~s}$, neoliberalism, in order to keep the market moving, accumulating and creating more capital, established a new speed of exchange. Technological developments continue to facilitate this increase in speed. 
I add further nuance to Harvey's definition of neoliberalism through the use of Berardi's idea of semiocapitalism, which focuses on what actually gets produced within capitalism. For Berardi, semiocapital "is not about the production of material goods, but about the production of psychic stimulation. The mental environment is saturated by signs that create a sort of continuous excitation, a permanent electrocution, which leads the individual mind as well as the collective mind to a state of collapse. ${ }^{\prime \prime}$ Berardi sums up the current psychic-physiological situation as follows:

While info-technologies are provoking an acceleration of the rhythm of information and experience, simultaneously the space for physical movement is shrinking and the resources for economic expansion are becoming exhausted. I call this double process of acceleration and exhaustion: the spasm. ${ }^{4}$

The speed of semiocapitalism and its inexorable endurance and exhaustion leads us to emotional depression since, as some critical theorists argue, we lack the ability to grow accustomed to this constant change in speed/rhythm. ${ }^{5}$ Berardi claims that depression is so widespread today because "the contemporary organization of production of surplus-value is founded on the phenomenon-the accumulation-of speed." ${ }^{16}$ If becoming a subject requires contemplation, care and practice, the socially imposed requirement of speed creates a tense situation for said subject. This tension between fast and slow is what brings about the condition of the "spasm." Berardi continues his observations by stating that "today's social/political problem" due to the "compulsive acceleration of daily rhythms" is the spasm, which "stems from economics of competition." According to Berardi, this spasm is a condition where "the body is less able to live and breathe in harmony with other bodies" because of the "precarisation (continuous competition between bodies) of work and daily life." ${ }^{7}$ In his more recent publication, Heroes: Mass Murder and Suicide, Berardi defines the spasm as a "sudden, abnormal, involuntary muscular contractions and relaxations." ${ }^{8}$ It is also "a sudden, brief spell of energy and an abnormal, painful intensification of the bodily nervous vibration." ${ }^{\prime 9}$ Clearly Berardi subsumes the corporeal experience into a universal presumably first world body, but how neoliberal semiocapitalism and its demands for speed, consumption and competition affects bodies choreographically is of concern here. The spasm interrupts the flow of semiocapitalist time, an efficient teleological progression, by highlighting the tension inherent in adhering to such ordering of time. Yet, I ask, how might the spasm be a productive corporeal interruption? What does the physicalized battle between being in and out of control at the same time look like when represented through popular screen dance choreography?

The aestheticization of the spasm could be said to function as what Guattari calls chaosmosis, "the creation of a new (more complex) order (syntony, and sympathy) emerging from the present chaos." ${ }^{10}$ This new order is about "the sharing of a sympathetic mindset." 11 In order to be able to find this new order, Guattari states we 
need a "chaoide," a living decoder of chaos that manages to avoid absorbing the negative psychological effects of chaos. ${ }^{12}$ Berardi adamantly calls for "us" (his readers presumably) "to produce and circulate chaoides ... tools for the conceptual elaboration both of the surrounding and of the internalized chaos. A chaoide is a form of enunciation (artistic, poetic, political, scientific) which is able to open the linguistic flows to different rhythms to different frames of interpretation." ${ }^{13}$ I read the choreography in these videos as representations of the spasm leading to the chaoide. My analysis of these videos suggests opportunities for thinking about how the corporeal labor of the spasm-especially its contingent sweat alongside (un)successful moments of corporeal fluidity-mark bodies as agents capable of negotiating how they might control their own embodied relationship to semiocapitalism.

Minoritarian discourses have allowed for women, queers, and people of color (and all intersectionalities within) to act, react, and contest the histories of subjugation, violence, and erasure these bodies have encountered. Furthermore, a strong case exists to suggest they have been living longer with the conditions that produce the spasm. I wonder how a theoretical contestation against the spasm might play out when the bodies doing or performing the spasm, i.e. white males, benefit from an ideological system that grants them privilege. In the videos I analyze, the music industry (as a mode of production) regulates the types of aesthetic and cultural capital recording artists have in order to generate economic capital. Thus, the novelty of a white male band, not known for choreographic display, showcasing its lead singer as an embodied subject or 'dancer' prompts me to wonder what types of neoliberal choreographies of white masculinities circulate in the music video genre. Although these three videos feature white male bodies dancing, I do not wish to imply that they are the only bodies capable of feeling the effects of semiocapitalism. Nor am I discounting the work of queer and women of color feminist theories that necessarily foreground the instability inherent in all masculine identities. ${ }^{14}$ Instead, I focus on how reading their bodies alongside the development of neoliberal semiocapitalism offers ways to both experience and exploit the corporeal effects of economics, politics, and technology. I hope to entertain a dialogue between masculinity studies and dance-a conversation often addressed in terms of men's roles in concert dance, cultural appropriation, and the white male body or spectatorship/the male gaze. It seems crucial now more than ever to assert what late social theorist and dance scholar Randy Martin wrote in Critical Moves, that "dance generates a sense of being in the midst of a crisis, a break, a rupture, even a loss and a prospect at the same time." 15

The white male body dancing in popular culture and the cultural implication this term contains sets up a possible contention to this essay. In setting these videos alongside one another, I do not attempt a taxonomy of white masculinity. Instead, I consider how the spasm as both a corporeal condition and a choreographic strategy functions 
in music videos as a way to watch how white masculinity reconfigures itself choreographically in the wake of a rather cataclysmic economic downturn brought about by the economic hubris of said first world white masculinity. Clearly, white masculinity arrives with its sets of privileges (even the privilege of using the spasm as an aesthetic/choreographic choice), but I want to draw our attention to how the spasm develops and emerges alongside the progression of neoliberalism, and how perhaps it can lead us to see its potential as a chaoide. The development of the discomfort, corporeal shock, (re)adjustment or spasm, I posit, can be traced progressively through these videos from the rigid, puppet-like contortions of David Byrne to the fidgets, wriggles, and the jittery posturings of Thom Yorke. If the spasm as chaoide can exist as a tactic to interrupt the smooth flow of semiocapitalism rather than as an uncomfortable corporeal modus operandi, then how might choreographers (particularly working within music video/popular screen) engage with its aesthetics to draw our attention to the urgency of such tactics for psychic-physiological survival?

Although I am specifically looking at representations of neoliberal white masculinities, I do not want to couch all of my analysis within the concept of hegemonic masculinity because it receives much scholarly criticism. Yet, as Connell and Messerschmidt state, "the pattern of embodiment involved in hegemony has not been convincingly theorized." ${ }^{16}$ They advocate for a continued interrogation and reconceptualization of hegemonic masculinity particularly through the significance of embodiment and its relationship to social context. Dance scholars welcome this call to arms (pardon the pun). Connell declares that in order to "understand embodiment and hegemony, we need to understand that bodies are both objects of social practice and agents in social practice." ${ }^{17}$ As both objects and agents, they respond to and resist institutional, economic, political, and social relations. Sometimes this response synchronizes well with the rhythms of life; other times it moves awkwardly out of time, out of synch, creating moments of tension, control, chaos, release and, for our purposes, spasms. In the case of hetero-masculinity and the white male bodies in the following analysis, the corporeal negotiations of the spasm, in other words, being in control and in synch versus displaying an apparent loss of control, becomes an identifying factor. Overall, my analysis marks a way to invite further interrogations about the relationship between corporeality, the corporeal discomforts of semiocapitalism, and how dance in music video often becomes a rich site for such discourses.

\section{Up in Arms: Talking Heads, “Once in a Lifetime" (1981)}

David Byrne appears to be stuck on an imaginary Ferris wheel that he himself must operate in the first images of the video for "Once in a Lifetime" directed by choreographer Toni Basil. It is as if this wheel represents the daily grind of the capitalist workplace, or, more precisely, serves as a metaphor for the labor all bodies must endure in order to maintain their gendered corporeality. Byrne exhales deeply, his 
cheeks expand outwards to demonstrate the laborious nature of his task. After what seems like the last circulation of his ride on this unseen wheel, Byrne jerkily stops and stands to face the camera. His body lies framed in mid-shot from his waist upwards. One hand rests below his sternum, while the other arm bends at the elbow in mid-air as if getting ready to swear to an oath.
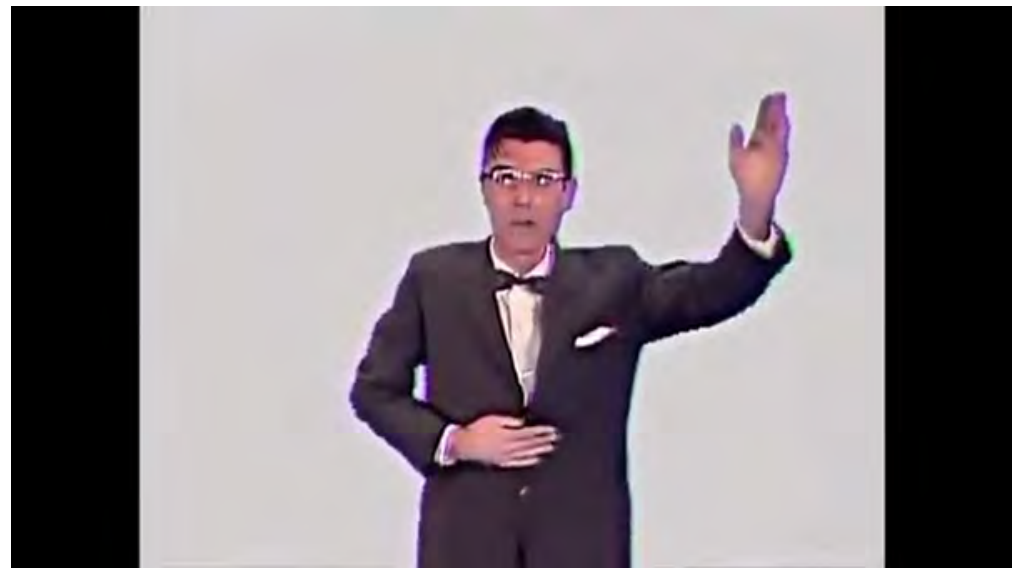

Screenshot, "Once in a Lifetime." Byrne begins his choreography with the proselytizer pose.

Dressed in a tan suit, bowtie, and glasses, Byrne could also be a great proselytizer, preparing to invite novices into his world of ideas. Austerlitz describes Byrne's appearance in this video as "part televangelist, part limbo dancer, and part children's show host, all bathed in the flop sweat of nerdy exertion." ${ }^{18}$ It is the sweat that interests me here. The labor of dancing, of having to follow a piece of choreography, might be alien to his body since Byrne is a singer/songwriter/musician, not a dancer. Yet, why draw attention to his sweat? His heavy breathing and sweaty brow instantiate the framework of the spasm, since "semiocapital arouses and mobilizes expression up to the point of a hyper-expressivity." ${ }^{19}$ He appears over-exerted, overexaggerated and over-worked, and the video has only just begun. Although semiocapitalism was arguably at its inception at the time of the filming, Byrne's character struggles with demands imposed on his body by the choreography and the narrative of the song's lyrics. The lyrics attest to an existential dissatisfaction he faces once he possesses material goods (e.g., beautiful automobile, beautiful house, beautiful wife) that exist as criteria for success within semiocapitalism. The emotional, physical, and cognitive labor required to 'succeed' literally trickles down from Byrne's brow as sweat. His inability to consistently stay within the ordered progression of neoliberal time (as evidenced by the constant self-reflexive questioning of the lyrics) creates small spasms, moments that demonstrate a loss of control and, perhaps worse, a total failure in executing the 'right' kind of corporeality -white, hyper-masculine, and economically viable-for neoliberalism. In this historical moment the 'right' kind of body was the "hard body" ${ }^{20}$ manufactured by the Ronald Reagan ideology.

Ronald Reagan was inaugurated as 40th US President in January 1981. Talking Heads' (USA) "Once in A Lifetime" single was released on 2 February 1981 and became a 
heavy rotation video on MTV after its broadcast debut in August 1981. Reagan's economic policies included his infamous "trickle down economics," or Reaganomics, which argued that tax cuts to corporations and the wealthy would result in a top down movement of capital that would improve the economy for all. Other economic policies during the Reagan administration included changes in the tax code, an explosion of military spending, a massive increase in the federal deficit, and a wholesale deregulation of industry that reinforced class divisions and led to an upward redistribution of wealth. ${ }^{21}$ However, this was not yet the reality in 1981. Reagan had only been in power for eight months when this video aired. Nevertheless, Byrne offers a sharp contrast to the corporeal bravado of Ronald Reagan. In Hard Bodies: Hollywood Masculinity in the Reagan Era, Susan Jeffords argues that the normative body set up was one that "enveloped strength, labor, determination, loyalty and couragethe"hard body" - the body that was, like Reagan's own, male and white." ${ }^{22}$ This "hardened male form" stood in as the synecdoche of the Reagan presidency, a form that Byrne's stiff and unregulated body undermines. ${ }^{23}$

Byrne seems like a harmless, effete nerd-boy in comparison to the Reagan ideal. ${ }^{24} \mathrm{His}$ sweat is evidence of his struggle to try to successfully em-body the "hard body" that can withstand anything. Byrne's stiffness is the wrong kind of hard. His body looks uncomfortably rigid, it falls to the front or side, and it cannot maintain its balance. In fact, it is hardly filmed facing forward-whether stably or comfortably. Instead, it moves chaotically, spasms with difficulty, and creates more and more sweat. Sweat that generates the Reaganesque strong, supple, upright body, is permissible; sweat from corporeal inefficiency is not. Byrne's body does not respond to the rhythm of the song, and any close-up of his body, particularly his face, displays the wrong kind of sweat. His arms seem listless without direction, needing external forces to engage them into action. In fact, when the second verse of the song begins, he is shot in full frame while his shoulders alternate in jerky spasms backwards, as if something, or an imaginary someone, is poking him violently each time his shoulders go back (and his arms flail backwards).
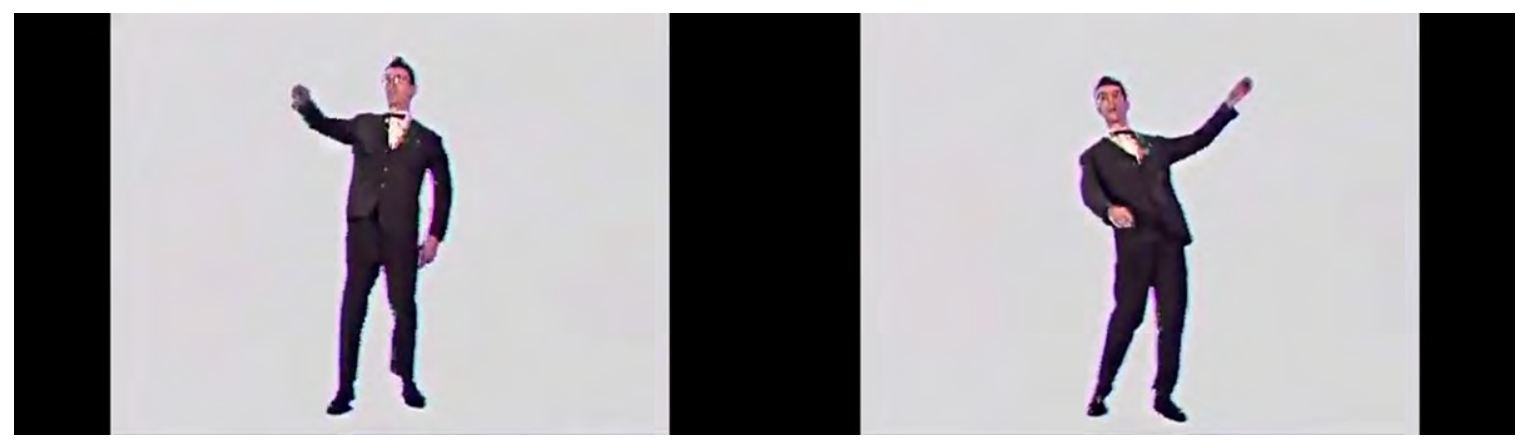

Screenshots, "Once in a Lifetime." Byrne lacks stability and balance. 
I read this inability to maintain composure and firm resistance as further confirmation of Byrne's failure to be a "hard body," for as Jeffords writes, "such bodies exist in the confirmation of this mastery by themselves refusing to be 'messy' or 'confusing,' but having hard edges, determinate lines of action, and clear boundaries for their own decision making" (my emphasis). ${ }^{25}$ His lack of "hard edges" contributes to his "messy" and "confusing" spasms. He is not in control since some-thing else forces his body to re-act, not enact.

Behind Byrne, a full body shot shows ethnographic footage of women of color kneeling close to the floor and pulsing their arms rhythmically in gestures mimetic of female domestic labor or possibly even of ecstatic spiritual worship. Byrne, in contrast, kneels and pulses his arms downwards with his palms flat, further instantiating his "soft body." Choreographer/director Toni Basil's interest in dances from the global South (an interest I am familiar with, having taken Afro Cuban dance classes with her in Los Angeles) may have been the catalyst for the use of ethnographic film footage and the appropriation of the choreographies within them. Basil explains that:

He [Byrne] wanted to research movement, but he wanted to research movement more as an actor, as does David Bowie, as does Mick Jagger. They come to movement in another way, not as a trained dancer. Or not really interested in dance steps. He wanted to research people in trancesdifferent trances in church and different trances with snakes. So we went over to UCLA and USC, and we viewed a lot of footage of documentaries on that subject. And then he took the ideas, and he "physicalized" the ideas from the documentary-style films. ${ }^{26}$

This physicalizing stems from the politics of appropriation and mass consumption that began to swell in the 1980s. It could also be read alongside the Reagan Doctrine's foreign policy particularly its influence in the so-called Third World as a way to combat the threat of the Soviet Union in that area of the world during the last decade of the Cold War. The mining of global South choreographies for source material points to the privileged and possibly self-serving agenda of US imperialism, but it also highlights how Byrne opted for embodiment outside of the early 1980s neoliberal hard masculine form. The tension produced by his inability to execute either a successful "hard body" or a "soft" feminine othered body (as portrayed by the choreography of the brown women in the ethnographic video) creates the spasms that riddle his body. The experience of neoliberal time by the subjects in the footage and Byrne himself is decidedly different, further demonstrating how bodies find ways to be in or out of control, causing them to spasm ... or not.

The song's chorus and its corresponding choreography features many Byrnes moving across the screen like cogs in the capitalist machine with arms in aggressive posturing, preparing for a pugilistic encounter with those Cold War enemies the Reagan Doctrine 
was keen on disarming. That Byrne in his nerdish guise appears ready to fight the good fight in honor of patriotism and deference to the Reagan Administration is laughable considering his criticism of said administration in his film True Stories (1986). ${ }^{27}$ However, his body's performance in the video attests to its attempt at incorpo-rating itself into Reaganomics; an unsettling, uncomfortable task full of agitation, instability, and spasms.
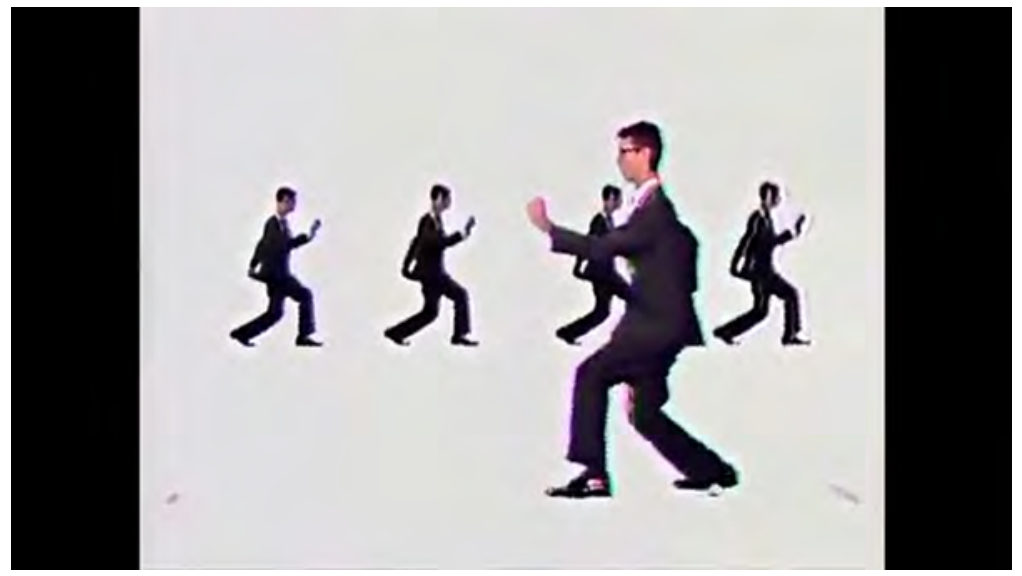

Screenshot, "Once in a Lifetime." Byrne as pugilistic cog in the machine.

As the video progresses, more ethnographic footage appears, this time of hands crossing on top of one another. Like before, Byrne imitates these as part of his choreographic score and he appears to be in time with the footage. Yet, when the chorus returns, his body spasms uncontrollably and he is no longer in control. It jerks, quivers and shakes while repeating arrhythmic motions that shift in intensity from slow and sustained to bound and fast. Basil had Byrne study epileptic seizure victims in order to learn how to spasm for the choreography. ${ }^{28}$ Here, the commodification of pain and illness for art/consumption belongs to the greater narrative of commodity culture and neoliberalism, those things that I consider as entities that Byrne's nerd boy contests. As the camera comes in for a close-up of his sweaty face, damp hair, and discombobulated gaze, he spasms so much that it appears as if outside hands (not his own) grab him on each side of his face to try to steady his shaking. He bends forward, rotates his torso around from the waist while the arms adjust on either side or move above his head as he comes back up during his rotation. This movement motif gets repeated later, rotations that call to mind the hands of a clock moving erratically and laboriously to tell time. These unsteady, uneasy, and perturbed corporeal spasms appear as if someone or something might be controlling his body. Although his attire suggests a Yuppie aesthetic, the young urban professional that emerged because of Reaganomics, Byrne's nerdish alter ego's discomfort with such an aesthetic manifests through the spasms. His is a white male body in conflict with the outside forces of Reaganesque hegemonic neoliberal masculinity. That someone/something must try to stop his spasms suggests the precarious nature of conformity especially during an era where conformity equaled success. Furthermore, Byrne appears in a different iteration of himself momentarily during this version of the chorus and jarringly breaks the 
distinction between Byrne as the out-of-control marionette and Byrne as the recording artist who appears settled, seated, and in control in the final moments of the video. I shall return to this still and non-sweaty Byrne shortly.

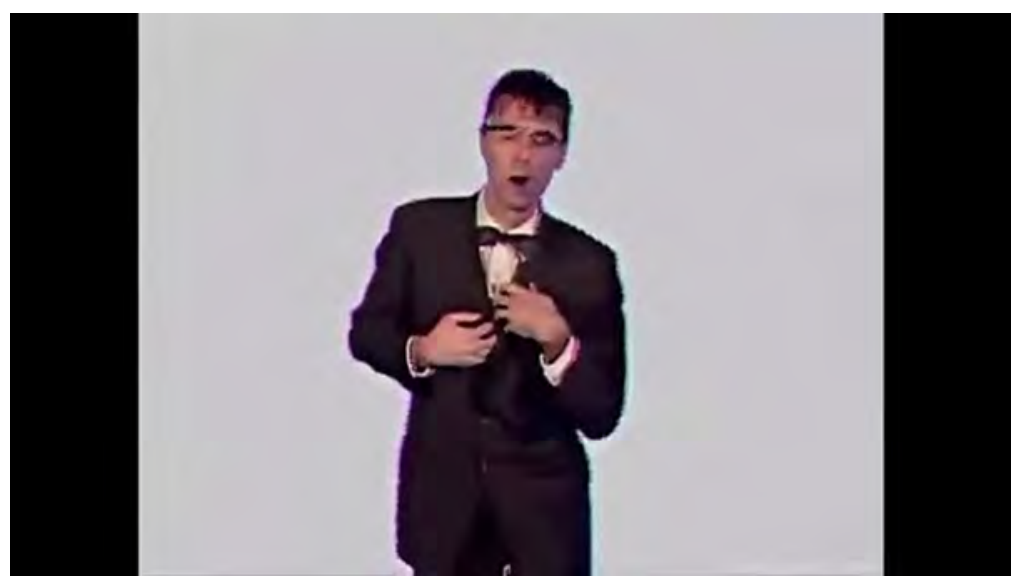

Screenshot, "Once in a Lifetime." Byrne in the middle of his spasms.

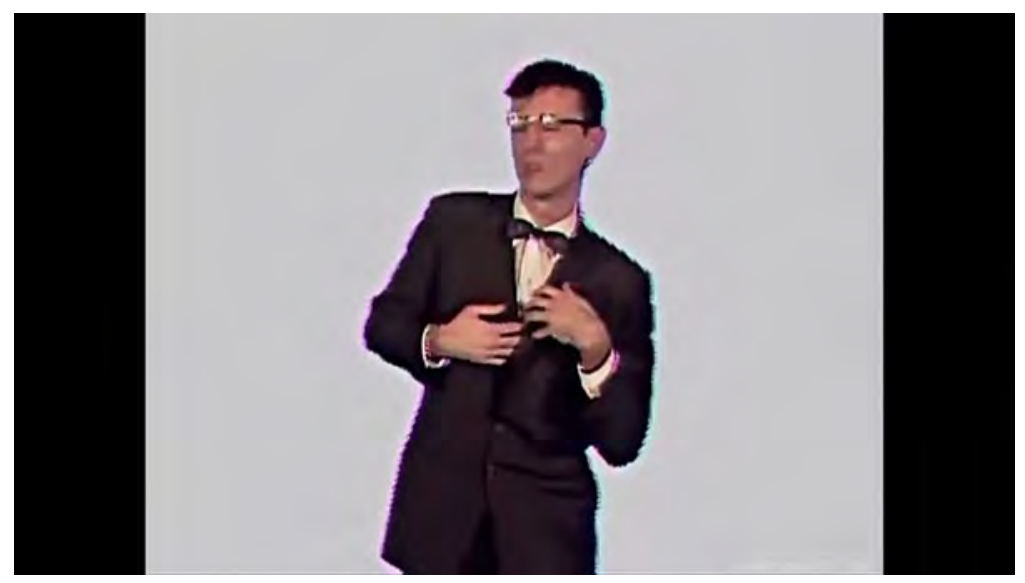

Screenshot, "Once in a Lifetime." Byrne continues to spasm.
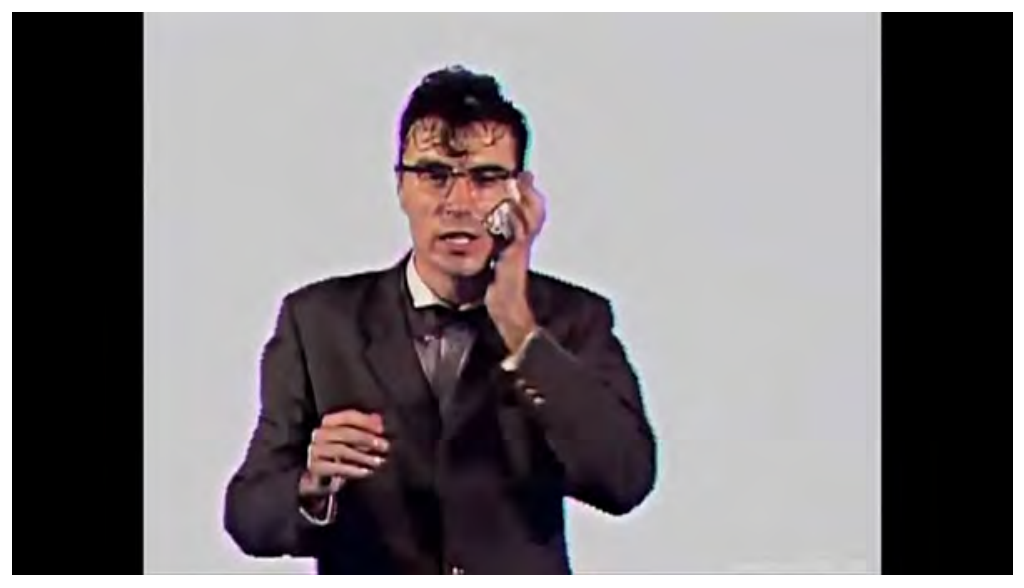

Screenshot, "Once in a Lifetime." Byrne wipes his sweat while trying to remain in control. 


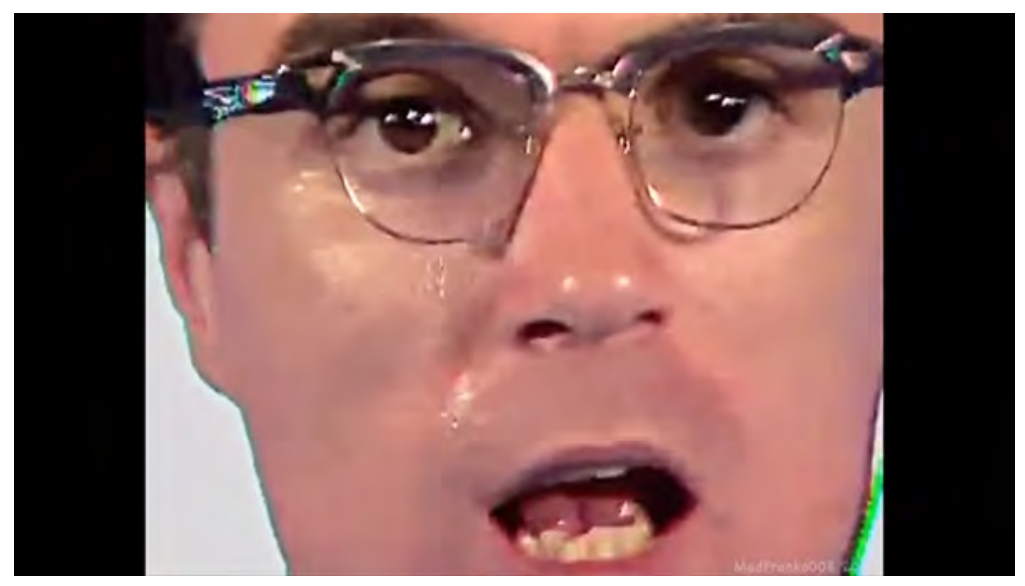

Screenshot, "Once in a Lifetime." A sweaty Byrne repeats "same as it ever was."

While the nerd Byrne spasms himself into the blue oblivion of the background, this other Byrne, who calmly lip synchs showing no signs of sweaty excess or discomfort, maintains a steady gaze with those of us behind and beyond the camera.

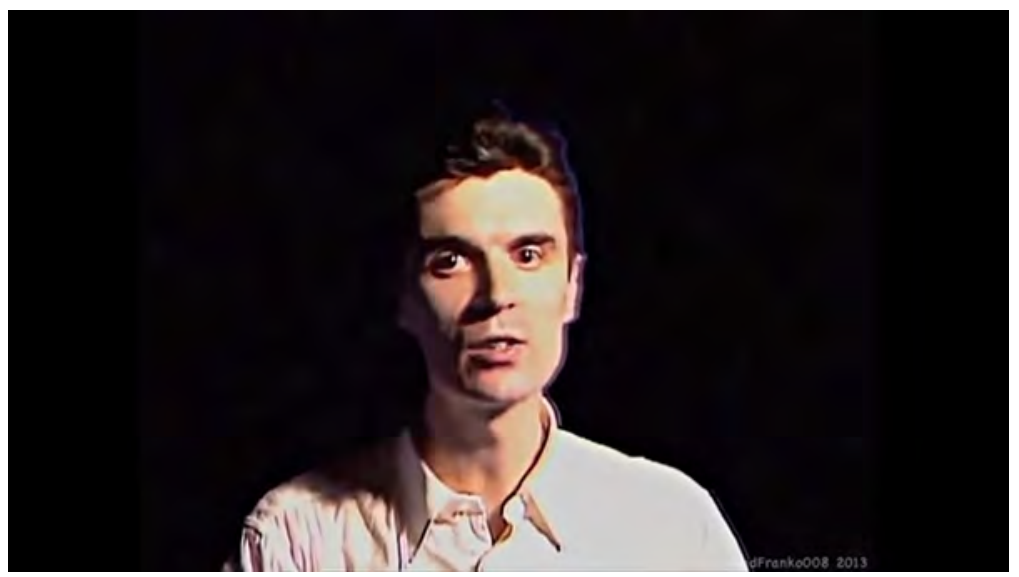

Screenshot, "Once in a Lifetime." Byrne the "rock star" stays in control without visible sweat.

As he repeats "same as it ever was" we are reminded that perhaps no matter how white male bodies resist and respond to and against socio-economic or cultural impositions, those that conform and uphold the "same" can continue to shape patriarchal capitalism in their own interest so that it indeed can be "same as it ever was." Those who cannot, must eventually spasm in order to endure.

\section{Dis-Arming the Spasm: Radiohead, "Lotus Flower" (2011) and Atoms for Peace, “Ingenue" (2013)}

"Lotus Flower" provides an aesthetics of austerity to parallel the economic slump that US/UK/EU faced after the 2008 financial banking crisis. In this video, with its stylized lighting, stark black and white cinematography and a black bowler hat, Thom Yorke of the UK band Radiohead spasms and contorts in ways that, I posit, mirror Berardi's precarization of work and daily life. Thirty years have passed since the "Once in a Lifetime" video first aired on MTV and "Lotus Flower," airing first on the Internet via 
VeVo and YouTube, engages with new modes of distribution and dissemination of the music video form. In examining the over thirty-year history of the music video form, media scholar Carol Vernallis writes, "Music video has since undergone shifts in technologies, platforms, periods of intense cross-pollination with other media, financial booms and busts, and changing levels of audience engagement. While music videos hit a low point in the [20]00s as budgets dried up, they have reemerged as a key driver of popular culture." ${ }^{29}$

Aesthetic requirements and styles may have shifted given the ways in which music videos are distributed today in contrast to the 1980s, when MTV had a board of 10 vetters who cleared material before it went to the Standards and Practices division. ${ }^{30}$ Now, many music videos for the major music conglomerates (and their high profile pop stars) compete not just for the attention of the viewer given our oversaturated image market, but for product placements and the most hits on YouTube. While it is difficult to qualitatively ascertain what material will receive more hits/views/circulation and why, in the case of the following two videos, it is the novelty of watching Thom Yorke, lead singer of Radiohead, dance that may have drawn over 35 million viewers (as of February 2016 on YouTube) to the "Lotus Flower" video.

As the music for "Lotus Flower" begins, Yorke dances in a frustrated fashion. His choreographer is Wayne McGregor. ${ }^{31}$ Yorke moves his arms and torso while his legs/feet stay in one place. He wriggles, swivels, and shifts from side to side. He sinks his torso inwards in concave fashion and has his hands shoved into his pockets in a gesture of nonchalance. He finds his way to one pose-left arm outstretched horizontally while the right arm is almost parallel but bent and stays closer to his torso. He pulses in this pose, repeating it as if on a digital loop, each repetition increasing in intensity until he makes a final sharp articulation of it and pauses. He acknowledges our gaze (the camera) and then abruptly shifts into spasmodic gestures that make him lose his balance as he jerks quickly backwards.

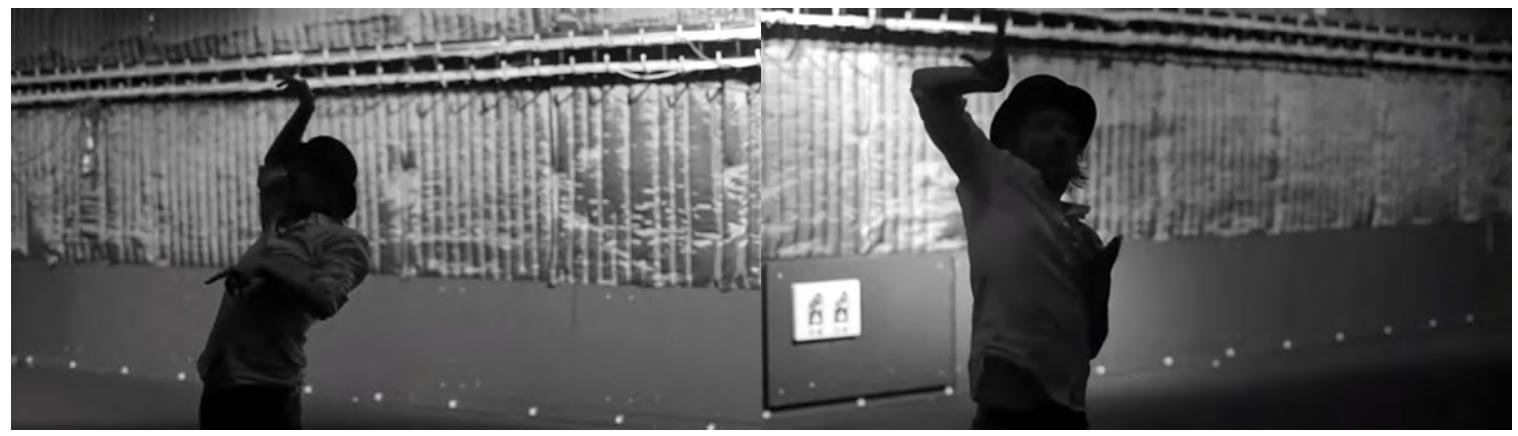

Screenshots, "Lotus Flower." Yorke stretches, writhes and wriggles. 


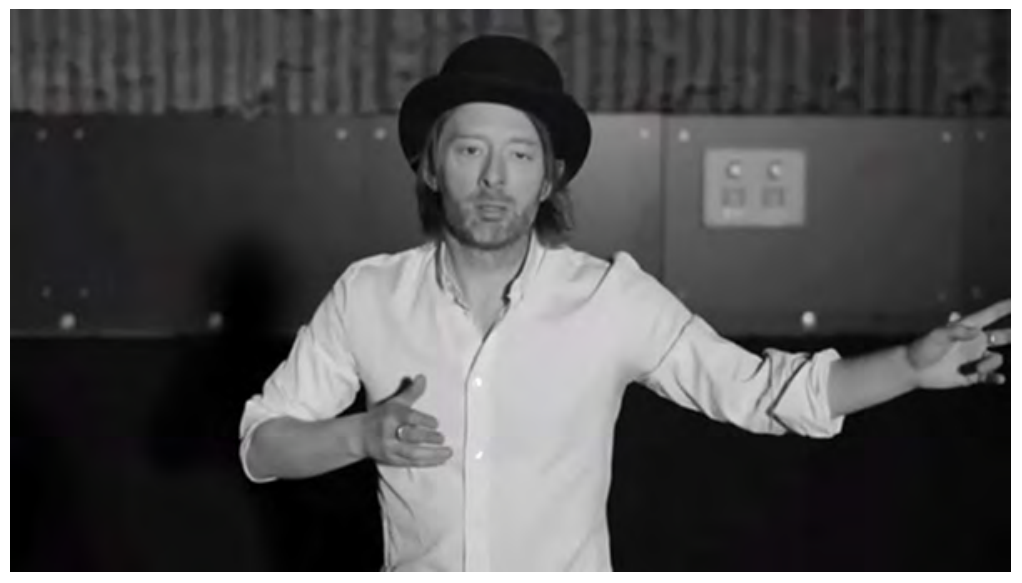

Screenshot, "Lotus Flower." Yorke finishes his intense repetition and acknowledges the camera's gaze.

Berardi writes that the "spasm emerges as an effect of a violent penetration of capitalist exploitation into the field of info-technologies which acts on the sphere of cognition, of sensibility, and the unconscious." 32 The stark warehouse, the even starker black and white cinematography and the stark imagery in the lyrics ("empty space inside my heart," "moon on a stick," "I dance around the pit / darkness is beneath") contrast with the active physicalizations of Yorke's body. It is as if his out-of-control limbs are "violently penetrating" the aestheticized tabula rasa of the backstage surroundings. Like Byrne before him, he physically struggles, caught between chaos/spasm and something else. Guattari would call this something else "complexity." Guattari develops the terms chaosmosis in order to re-define subjectivity. For him, chaosmosis is a "dance of chaos and complexity" 33 that individuals within neoliberalism (or semiocapitalism) must attune themselves to. As such, Yorke's chaotic spasms enact the chaosmosis of his austere surroundings and the austerity that riddled the world financial markets when the video was produced. In contrast to Byrne's nerd boy who was unable to embody the masculine "hard body" of his historical moment, Yorke's spasms demonstrate a new struggle after the economic downturn post 2008. It is not so much a struggle to become more masculine, rugged, or powerful, but rather an engagement in a metaphoric struggle with how to regain balance after so much economic and psychic-social upheaval.

Yorke finds his physical balance again by running in place until that movement transforms into arms reaching forward, grabbing at intangible objects. He circles around in a running pattern again which leads to a quick edit showing him standing still in a full body shot. He appears mesmerized by his left palm as he looks over at it and slowly begins to raise his hands over his face. The camera zooms in to a medium shot and his gaze moves from the left palm to the right hand/arm lifted high above his head. His eyes look up, he removes the bowler hat from his head and we see damp hair, a sweaty forehead, and a large sweat spot at his armpit. 


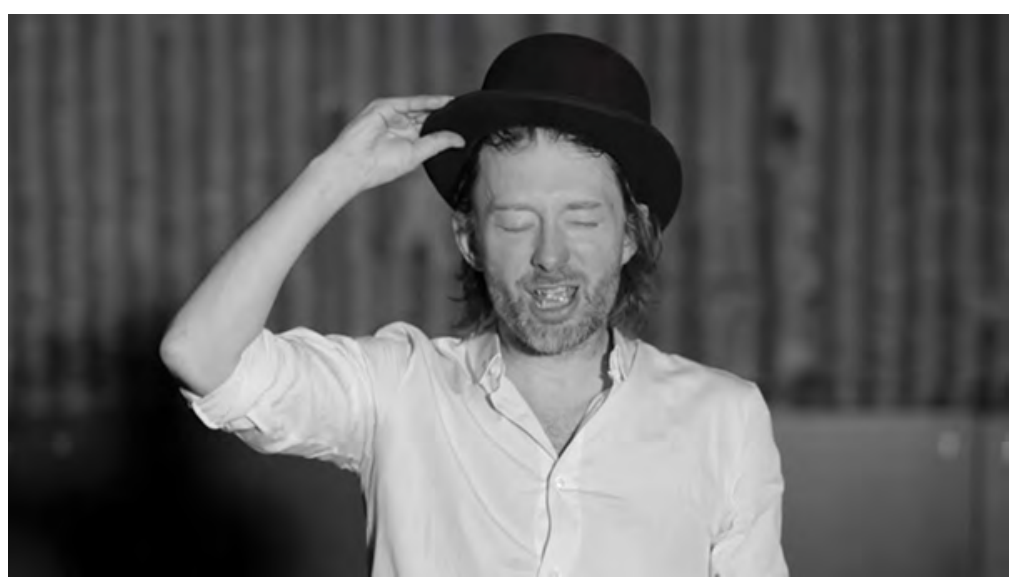

Screenshots, "Lotus Flower." Yorke takes a break from his spasms to remove his hat.
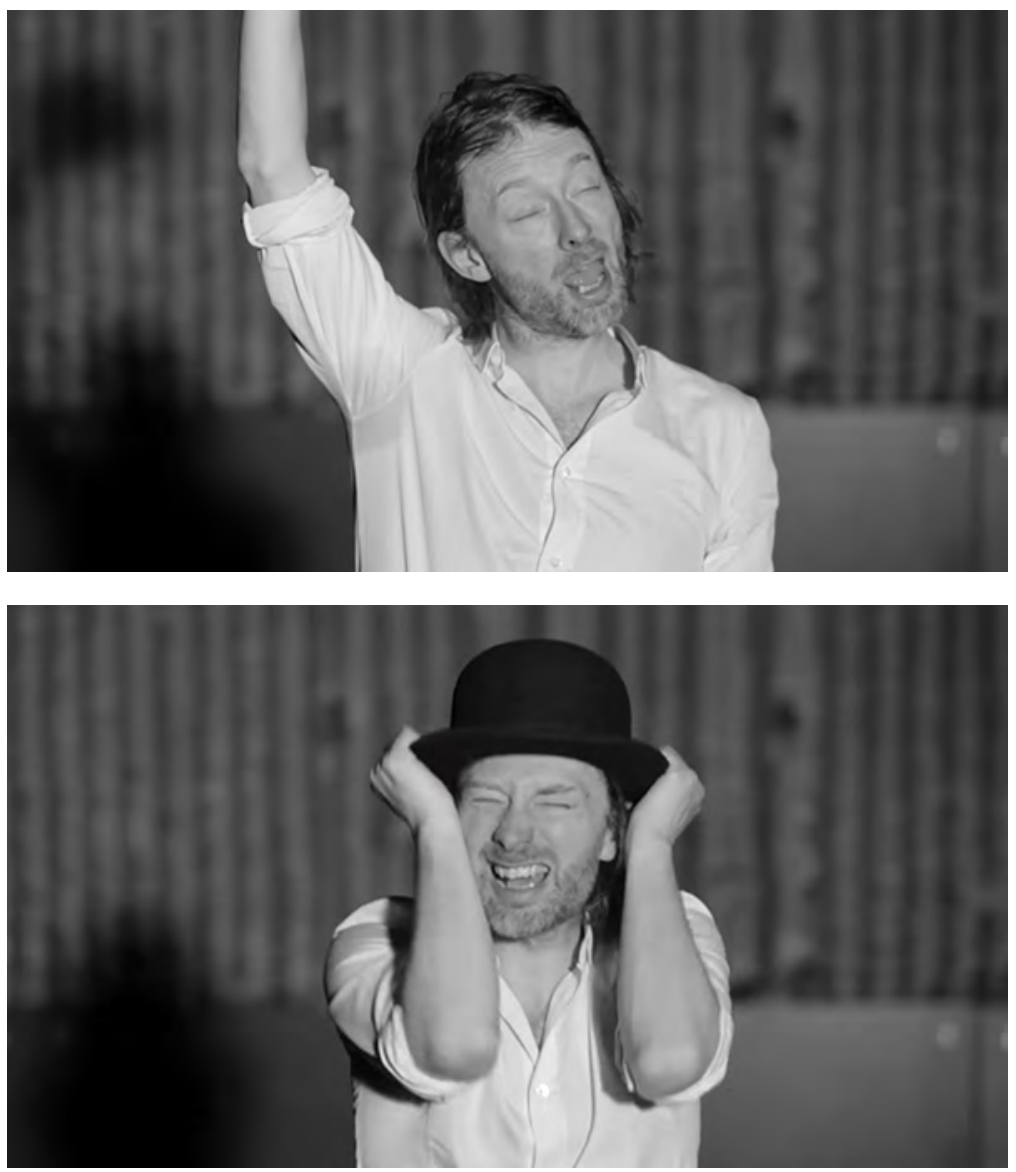

This short, almost languorous gesture of ecstasy meets a spasmodic end as by the time he brings his arm down and replaces the hat on his head, he breaks into jerky, quivering spasms while he runs in place. As Berardi explains, "the spasm is the panic effect of the accelerated stimulation of the organism." ${ }^{34}$ The spasm has caused his body to sweat, become unruly and to labor inefficiently. He runs, yet he doesn't go anywhere, representing the futility of corporeal labor during neoliberal austerity. He 
remains stuck in a push-pull between moments of slowness and ease with other moments of twitching and trembling dis-ease.

For the second verse, the same choreographic idea of gestures in intensified repetition returns. This time the camera changes location. It is set up higher and at a different side-ways angle. He continues to balter about, moving between losing his balance and trying hard to regain it. He kneels, claps, and loses his balance as if the ground can no longer offer stability in a clear choreographic metaphor of the experience of the financial crisis and its ensuing austerity measures. The close-up returns after this moment of imbalance. Yorke has a look of contemplative consideration with hands in what appears like a prayer position. He removes his hat once more before the jiggles, wriggles, and jerks return. His shoulders lift up and down, his legs flail and kick around, his torso cannot find proper alignment. There is no stability for him here. For the final 44 seconds of the video, Yorke is in a constant state of spasm.

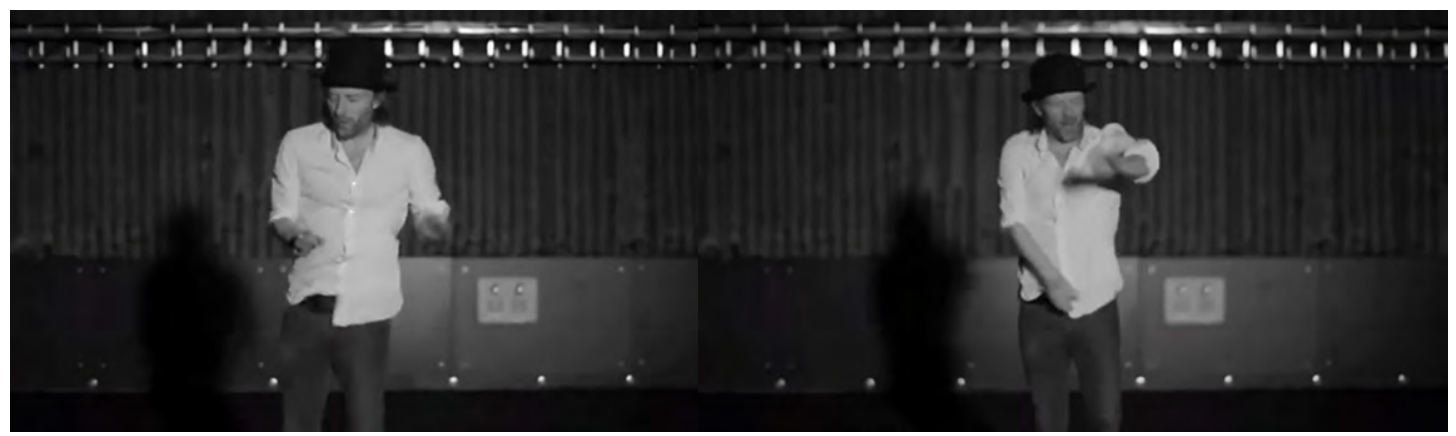

Screenshots, "Lotus Flower." Yorke continues to spasm as the music video draws to a close.

"What should we do when we are in a situation of spasm?" asks Berardi. ${ }^{35}$ In Yorke's case, it involves giving into it somewhat, not with defiant recalcitrance (that may create more spasms), but with cautious practice since, as a white male body marked with privilege, discomfort and spasm is a new precarious embodiment to learn.

Wayne McGregor continued his collaboration with Thom Yorke with Atoms for Peace, a collaborative project between Yorke, Flea (of Red Hot Chili Peppers) and other indie rock musicians. In "Ingenue," a tweed-suited Yorke mirrors choreography begun by dancer Fukiko Takase, a member of McGregor's Random Dance company. This is a fun video to watch in terms of the noticeable differences between their two distinctively articulate bodies executing the same movements. More importantly, both genders wrestle with the spasm in this video. The contrast in their bodies goes further: his whiteness, her Asianness, his untrained body, her dance-trained one. Evidence of competition could be read within the video: both do the same movements, both are dressed alike, calling to mind the equal compensation objective for women in the corporate workplace, something that began in 1980s. 
"Ingenue" begins on a dance theater stage. A white screen comes down while Takase, dressed in a brown tweed three-piece suit, stands still, eyes closed. The camera changes and comes closer (in similar fashion to "Lotus Flower") and we now see her from the side, off-center. The choreography begins. It features an over-exaggerated walk in place with knees raised high, arms swinging forward and backward like lazy pendulums, and her body weight is slightly backwards. She appears to be walking up an imaginary hill.

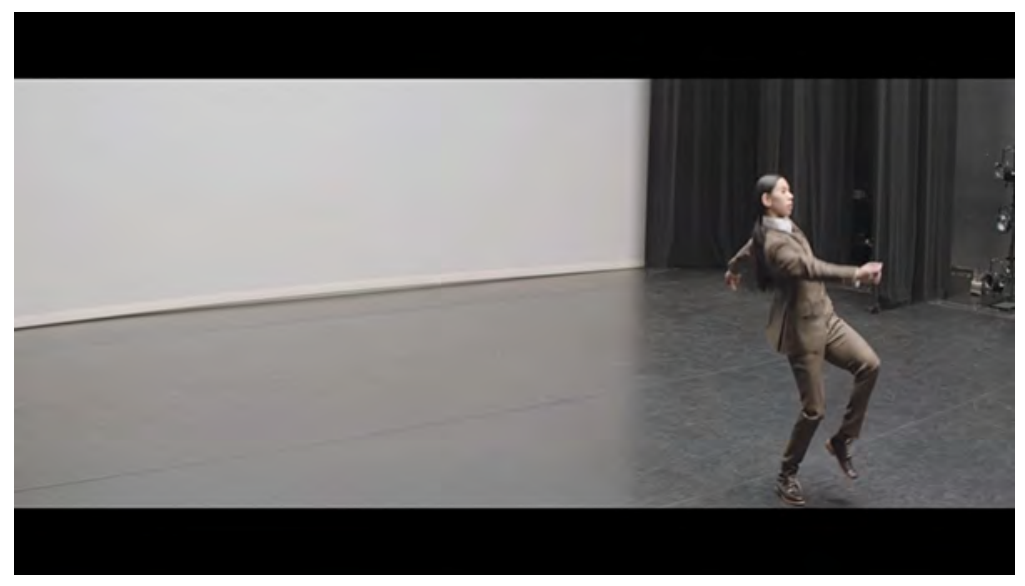

Screenshot, "Ingenue." Takase in the middle of her exaggerated walk.

When she turns to circle in place, a sharp edit makes Yorke appear in her place, doing the same choreography ... slightly differently. His movements are not as fluid nor as expansive as hers. Yet, their partnering could be read as a new order emerging from chaosmosis, with order "understood as harmony between mind and the semioenvironment, and also a sharing of the same mind-set: sympathy as common perception. ${ }^{36}$ While Berardi (and Guattari) privilege the mind here, I prefer to see the harmony in bodies, particularly in the harmoniously edited shift between Yorke and Takase's performances of similar choreographic phrases.

She kneels and thrusts her torso bending forwards while covering her head with the blazer's coattails. He does the same. The editing keeps jumping from her to him as if one starts the choreographic phrase while the other continues or ends it. This shared choreographic labor occurs until she suddenly jumps out from behind him while he rests in a pose with his arms up and across in an L-shaped formation.

They begin to dance together, mirroring one another. Their partner work includes side-to-side movements, level changes, and tracing uneven lines in space with their bodies. It is as if they are each trapped inside a plastic bag and trying to feel their way out by bending, writhing, and flicking their limbs in asymmetrical patterns. 


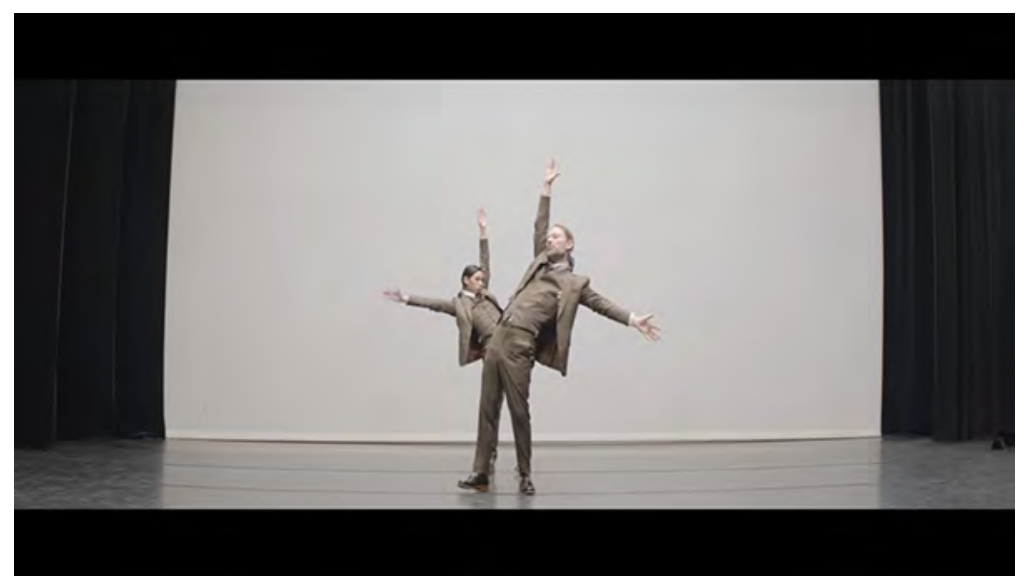

Screenshot, "Ingenue." Yorke and Takase occupy the stage space together for the first time.

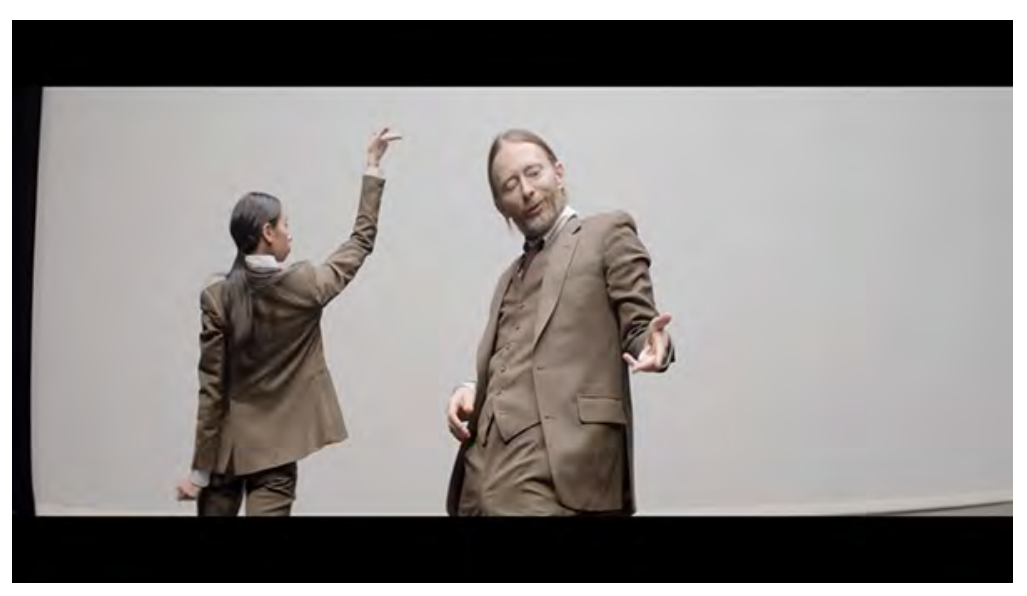

Screenshot, "Ingenue." Together they engage in stylistic, spasmodic phrases.

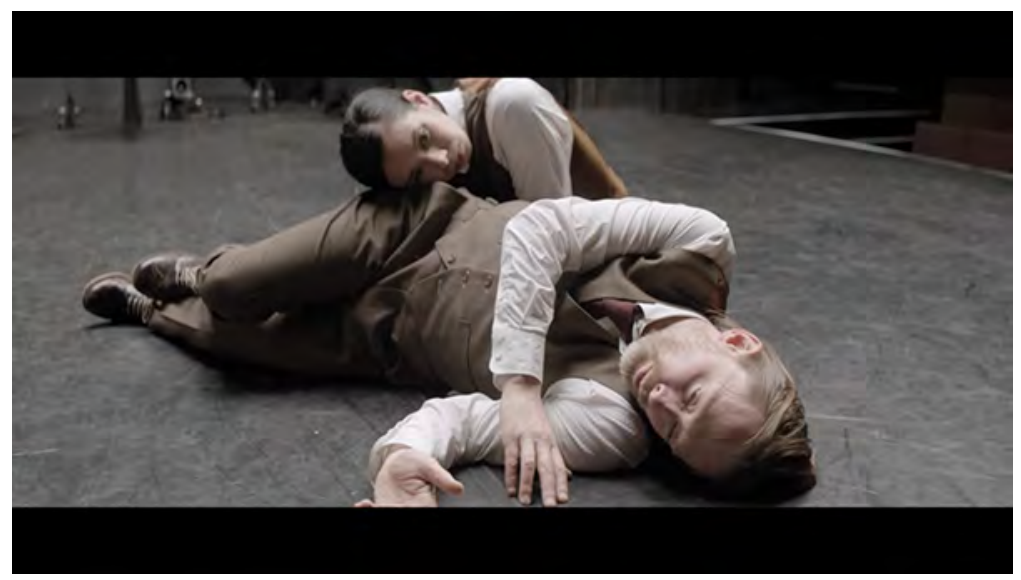

Screenshot, "Ingenue." Takase and Yorke enjoy a brief moment of stillness.

They eventually find a moment of respite from their twitching postures and gestures and they lie on the floor. At one point, Yorke lies sideways and Takase rests her head on his hip. The unexpected rhythmic variation between the intense jerks and the slow, almost still poses materializes the variability of neoliberal time.

As Deleuze and Guattari write in What Is Philosophy?, "This is the instant of which we do not know whether it is too long or too short for time. We receive sudden jolts that beat like arteries. We constantly lose our ideas." ${ }^{37}$ This shift from chaos to stillness 
could also be read as what Guattari articulates as "an initial chaosmotic folding [which] consists in making the powers of chaos co-exist with those of highest complexity." ${ }^{38}$ It is this moment of slowness, of stillness, or more specifically of temporal complexity that begins to shift the spasms in this video from mere representations of lack of control, inefficiency and messiness to the possibility of seeing them as chaoides; especially since Takase demonstrates such corporeal elegance and fluidity in her embodiment of them.

Interestingly, these two videos rely on full-body shots for the majority of the time. Only at decisive moments in the songs does the camera offer a close-up of each of their faces. They contort their faces similarly: eyes tucked upwards into their lids, features slightly twisted, an un-self-conscious reflection into what dancing or the music might offer: unbridled release from the social inscriptions that write the body. I am reminded of what cultural geographer David Harvey writes: "a body is not a closed and sealed entity but a relational 'thing' that is created, bounded, sustained, and ultimately dissolved in a spatiotemporal flux of multiple processes." ${ }^{\prime 39}$ These close-ups might be short moments where their choreographed bodies offer ways to dismantle or disturb the apparent chaos of the spasm. They are chaoides, "the living decoders of chaos that manage to avoid absorbing the negative psychological effects of chaos" by learning how to manage the struggle through corporeal fluidity.

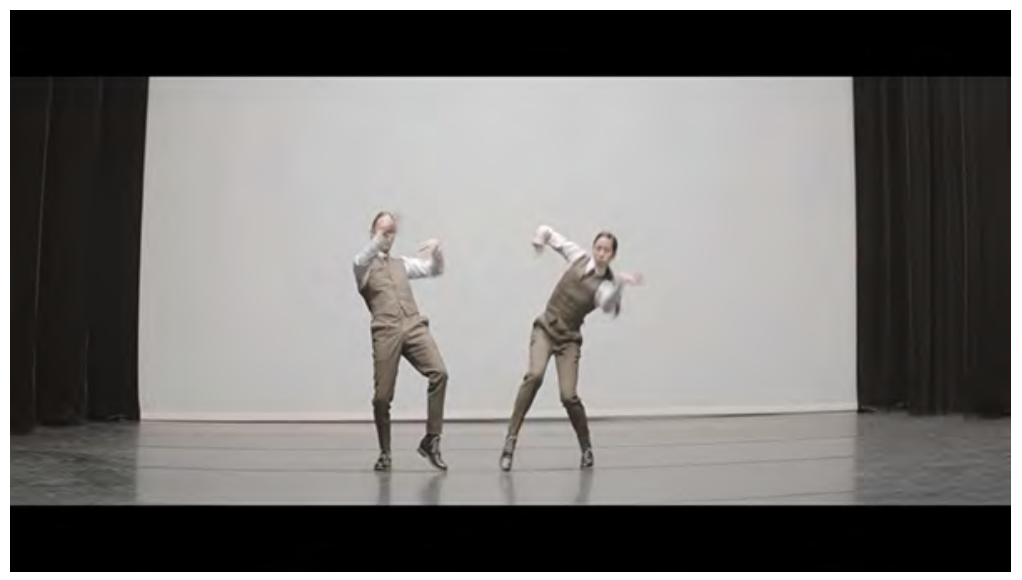

Screenshot, "Ingenue." The final spasms they perform together.

"Ingenue" concludes with both Yorke and Takase jerking and spasming uncontrollably after their brief, sympathetic respite on the floor. They flail, flounce and jostle. Limbs askew, feet in place, gaze directed forwards or upwards. Eventually, she moves behind him, disappearing from view as the camera pulls out and shows a solo Yorke, standing still, slowly lowering his bent arms. Their visible embodied differences highlight the need to work in synchrony and sympathy with others in order to materialize Guattari's chaoides, particularly in this historical moment that privileges competition and individual success. Perhaps the only way to endure the spasm is through embodied exchanges, especially with bodies (such as Takase's) that are practiced in skillfully enunciating their chaos and complexity within and outside of semiocapitalist time. 


\section{Biography}

Dr. Melissa Blanco Borelli is Senior Lecturer in the department of Drama and Theatre (soon to be Drama, Theatre, and Dance) at Royal Holloway, University of London. Her publications include She is Cuba: A Genealogy of The Mulata Body (Oxford University Press, 2015) and The Oxford Handbook of Dance and the Popular Screen (OUP, 2014). Chapters and journal articles appear in Women and Performance: a journal of feminist theory, Zizek and Performance (Palgrave, 2015), Black Performance Theory (Duke UP, 2015), and The Oxford Handbook of Screendance (forthcoming). Currently, she is on the lookout for a new book project.

Email: Melissa.Blanco@rhul.ac.uk

\section{Notes}

${ }^{1}$ I would like to thank Sherril Dodds for her comments to a very rough draft version of this essay. Derek Burrill suggested some of the books I consulted and was on hand for preliminary conversations. I would like to thank PoP Moves conference participants at UEL where I presented the first draft of this essay. My anonymous readers at IJSD were brilliant in their criticisms. Harmony Bench helped me focus theoretically and pare down what began as an overly ambitious hodge-podge of critical theory, music video analysis, and very long dance descriptions. Thank you Harmony and Simon Ellis for your patience. Lastly, I'd like to thank Nadine George-Graves who attended the panel where I presented a working draft at SDHS Conference in Trondheim, Norway. Her comments were very helpful especially since she was not initially convinced by the ideas. Trying to convince a skeptic always makes you work just a little bit harder, so thank you, Nadine.

${ }^{2}$ David Harvey, Neoliberalism, 2.

${ }^{3}$ Franco Berardi, Precarious Rhapsody, 45.

${ }^{4}$ Berardi, Heroes, 216.

${ }^{5}$ See Elizabeth Povinelli, Economies of Abandonment. Povinelli proposes the ideas of endurance and exhaustion as related to capitalism in late liberalism (neoliberalism). I am drawn to this combination because endurance and exhaustion relate to time, rhythm, and the event of a social project.

${ }^{6}$ Berardi, Heroes, 10.

${ }^{7}$ Berardi, CalArts TedX.

${ }^{8}$ Berardi, Heroes, 217.

${ }^{9}$ Ibid. 
${ }^{10}$ Félix Guattari qtd. in Berardi Heroes, 220.

${ }^{11}$ Ibid.

12 Idem., 222.

${ }^{13}$ Ibid.

14 As R. W. Connell and James W. Messerschmidt helpfully gloss in Hegemonic Masculinity, "Feminist theories of patriarchy include works by Goode (1982) and Snodgrass (1977). Maxine Baca Zinn (1982), Angela Davis (1983) and bell hooks (1984) articulate the race bias when it comes to speaking about sex difference, while Broker (1976) and Plummer (1981) examined 'gay men's ambivalent relationships to patriarchy and conventional masculinity"' (832). Eve Kosofsky Sedgwick's "Gosh, Boy George" usefully removes the association of masculinity with men to complicate the social enactments of gender.

${ }^{15}$ Randy Martin, Critical Moves, 1.

${ }^{16}$ Connell and Messerschmidt, Hegemonic Masculinity, 851.

17 Ibid.

${ }^{18}$ Saul Austerlitz, Money for Nothing, 55.

${ }^{19}$ Berardi, Chaosmic Spasm, 186.

${ }^{20}$ See Susan Jeffords, Hard Bodies.

${ }^{21}$ David Savran, Taking it Like a Man, 164.

22 Jeffords, Hard Bodies, 25.

${ }^{23}$ Ibid.

${ }^{24}$ Jeffords traces how masculinity was constructed during the Reagan Administration in the USA, linking Reagan's own Hollywood screen history to his presidential persona and the types of male characters that emerged in Hollywood action films.

${ }^{25}$ Idem., 27.

${ }^{26}$ Greg Prato, 2011 qtd in Songfacts.

27 True Stories (1986) directed by Byrne which fuses satire, documentary, and music to tell the story of a fictional small town in Texas preparing to celebrate its $150^{\text {th }}$ anniversary. As a "window" into 1980s Americana, the film subtly critiques Reagan era cultural ideologies.

${ }^{28}$ See Songfacts.

${ }^{29}$ Vernallis, Unruly Media, 207.

${ }^{30}$ Idem., 208.

${ }^{31}$ Wayne McGregor Random Dance received a 29\% increase in Arts Council funding for 2012-something interesting to note given the budget cuts affecting UK artists during the Tory austerity measures. (London Dance)

32 Berardi, Chaosmic Spasm, 184.

${ }^{33}$ Guattari, Chaosmosis, 88.

${ }^{34}$ Berardi, Chaosmic Spasm, 187.

${ }^{35}$ Idem., 184.

${ }^{36}$ Idem., 187.

${ }^{37}$ Gilles Deleuze and Félix Guattari, What Is Philosophy?, 201. 
${ }^{38}$ Guattari, Chaosmosis, 110.

${ }^{39}$ Harvey, Spaces of Hope, 98.

\section{References}

Austerlitz, Saul. Money for Nothing: A History of the Music Video from the Beatles to the White Stripes. New York: Continuum International Publishing Group, 2007.

Berardi, Franco 'Bifo.' Precarious Rhapsody: Semiocapitalism and the Pathologies of the Post-Alpha Generation. London: Minor Compositions, 2009.

. CalArts TedX:Performance, Body and Presence. 9 March 2013.

http://tedxcalarts.org/livestream/

. "Chaosmic Spasm and the Educational Chaoide" in Deleuze and Guattari Politics and Education: For People-Yet-To-Come. Edited by Matthew Carlin and Jason Wallin. London: Bloomsbury Press, 2014.

. Heroes: Mass Murder and Suicide. London: Verso Books, 2015.

Connell, R.W. and James W. Messerschmidt. "Hegemonic Masculinity: Rethinking the Concept" Gender \& Society December 2005 19: 829-859.

http://dx.doi.org/10.1177/0891243205278639

Deleuze, Gilles and Félix Guattari. What is Philosophy? New York: Columbia University Press, 1994.

Guattari, Félix. Chaosmosis: An Ethico-Aesthetic Paradigm. Bloomington: Indiana University Press, 1992.

Harvey, David. Spaces of Hope. Berkeley: University of California Press, 2000.

. A Brief History of Neoliberalism. New York: Oxford University Press, 2005.

"Ingenue." Dir. Garth Jennings. Atoms for Peace. 2013. YouTube.

https://www.youtube.com/watch?v=DpVfF4U75B8

Jeffords, Susan. Hard Bodies: Hollywood Masculinity in the Reagan Era, New Brunswick:

Rutgers University Press, 1994.

“Lotus Flower." Dir. Garth Jennings. Radiohead. 2011. Vimeo.

https://vimeo.com/20751513 
London Dance. "News: Arts Council funding announcements." 30 March 2011. Accessed 18 Feb. 2016. http://londondance.com/articles/news/arts-council-fundingannouncements/.

Martin, Randy. Critical Moves: Dance Studies in Theory and Politics. Durham: Duke University Press, 1998.

“Once In A Lifetime." Dir. Toni Basil. The Talking Heads. 1981. Vimeo.

https://vimeo.com/97541390

Povinelli, Elizabeth. Economies of Abandonment: Social Belonging and Endurance in Late Liberalism. Durham: Duke University Press, 2011.

http://dx.doi.org/10.1215/9780822394570

Prato, Greg. MTV Ruled The World: The Early Years of Music Video. Self-Published, 2011.

Savran, David. Taking it Like a Man: White Masculinity, Masochism, and Contemporary American Culture. Princeton: Princeton University Press, 1998.

http://dx.doi.org/10.1515/9781400822461

Sedgwick, Eve Kosofsky. "Gosh, Boy George, You Must Be Awfully Secure in Your Masculinity." Constructing Masculinity. Ed. Maurice Berger. New York: Routledge, 1995. 11-19.

Songfacts. "Once In A Lifetime by Talking Heads." The Top 13. Retrieved 13 Aug. 2011. Accessed 6 Nov. 2015. http://www.songfacts.com/detail.php?id=1867

Vernallis, Carol. Experiencing Music Video: Aesthetics and Cultural Context. New York: Columbia University Press, 2004.

Vernallis, Carol. Unruly Media: YouTube, Music Video and the New Digital Cinema. New York: Oxford University Press, 2013.

http://dx.doi.org/10.1093/acprof:oso/9780199766994.001.0001 